\title{
AN INTEGRATED AHP AND WEIGHTED FUZZY GOAL PROGRAMMING MODEL FOR IS PROJECT SELECTION
}

\begin{abstract}
The purpose of this paper is to develop an integrated AHP and Fuzzy Goal Programming methodology which deals the imprecise data and offer more flexibility. The proposed method includes the following steps: At first, an expert team is formed which identifies the decision criteria and alternatives and builds a hierarchical model for IS project selection. After that, the AHP is used in order to obtain weights of each criterion and project. At the end, a Weighted Additive Fuzzy Goal Programming model (WAFGP) is formulated and used to complete the project selection decision. In order to illustrate the use and advantages of this approach; a hypothetical example has been exposed. The results show the quality of the support which the proposed model provide to the IS project selection decision. Despite its advantages, the methodology proposed here neglects the uncertain nature of decision maker's judgment and the interdependencies among criteria and alternatives.

Keywords: Information systems, project selection, Analytic hierarchy process (AHP), Weighted Additive Fuzzy Goal Programming.
\end{abstract}

\section{Introduction}

Us a multi-criteria decision making, IS projects selection has to consider a large number of alternatives, multiple and often conflicting, fuzzy and imprecise attributes, and also interdependencies among this alternatives and criteria. However, if the existing methods reported in literature consider the diversity of the attributes and the interdependencies problems, they neglects the imprecise and fuzzy nature of this attributes. Furthermore, the Preemptive/Lexicographic Goal Programming used is not flexible when dealing with integer problem with many goals. This paper proposes a hybrid method using AHP and Weighted Additive Fuzzy zero-one goal programming in order to deals with this limits.

\section{Literature Review}

During the last decades, several methodologies have been developed to overcome the IS project selection difficulties. As for example, Schniederjans \& Wilson (1991) have proposed an AHP- zero-one linear programming methods to consider budgetary and resource constraints. After that, Lee \& Kim (2001) have developed an integrated DelphiANP-ZOGP models to estimate the degree of interdependencies among IS projects. Finally, to deal with the imprecise data in IS projects and uncertain judgment of decision makers; Bolat and al. (2014) have developed an integrated fuzzy AHP - fuzzy multi-objective linear programming model. Beyond the progresses, some weaknesses still characterize the IS project selection methodologies. Actually, the Preemptive/Lexicographic Goal Programming (with priority) used in almost of the studies is not flexible when dealing with integer problem with many goals.

\section{Objectives}

The aim objective of this paper is to present a hybrid method using the analytic hierarchy process (AHP) proposed by Saaty (1980) and the Weighted Additive Fuzzy Goal Programing (WAFGP ) proposed by Yaghoobi \& al. (2008) to offer more flexibility.

\section{Research Design/Methodology}

The proposed methodology includes the following steps: At first, the decision criteria and alternatives are identified and a hierarchical model for IS project selection is constructed. 
After that, the AHP is used in order to obtain weight of each criterion. At the end, a WAFGP model is formulated and used to complete the project selection decision.

\section{An Illustrative Application}

In order to illustrate the use and advantages of the proposed methodology, a hypothetical example is described as follows. Suppose that a firm have to choice 05 information system projects among 10 alternatives. For this decision, 11 criteria that appear on the figure 01 have been considered.

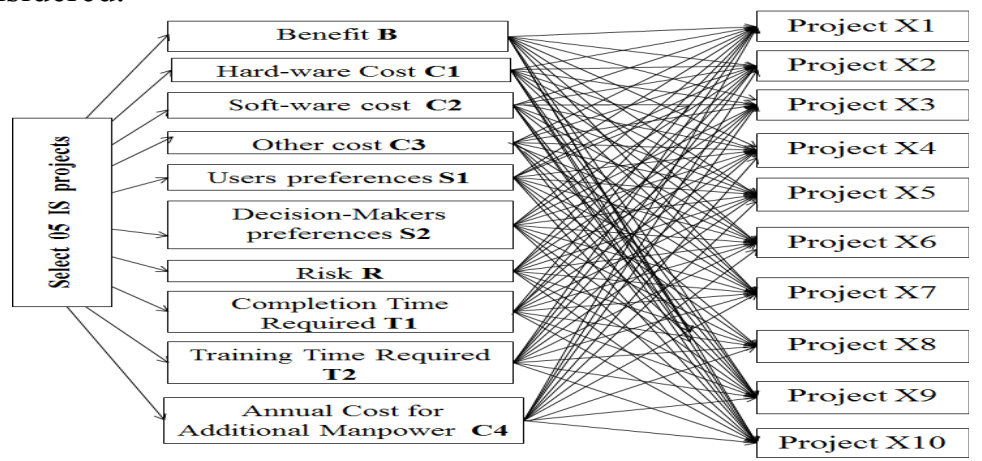

Fig 1. AHP hierarchy

At first, the hierarchy model exposed in the figure 01 has been constructed and the attributes and alternatives have been presented to the project team members to extract judgment matrices with a nine-point scale at each level. The software SUPERDECISION have been then used to determine the normalized weights and synthesize the results. Table 01lists the Pairwise Comparison Judgment Matrices and the relative weights of attributes. The decision makers were fairly consistent in ranking the attributes. Indeed, the consistency indexes have been less than the threshold value 0.1 (Saaty, 1980).

Table 01: Pairwise comparison judgment matrices and relative weights of attributes

\begin{tabular}{|c|c|c|c|c|c|c|c|c|c|c|}
\hline & C1 & $\mathrm{C2}$ & $\mathrm{C3}$ & $\mathrm{C4}$ & B & $\mathbf{R}$ & T1 & T2 & S1 & S2 \\
\hline C1 & 1 & 1 & 3 & 3 & 2 & 2 & 3 & 4 & 3 & 3 \\
\hline $\mathrm{C} 2$ & 1 & 1 & 3 & 3 & 2 & 2 & 3 & 4 & 3 & 3 \\
\hline C3 & $1 / 3$ & $1 / 3$ & 1 & 2 & $1 / 2$ & $1 / 3$ & 2 & 3 & 3 & 3 \\
\hline C4 & $1 / 3$ & $1 / 3$ & $1 / 2$ & 1 & $1 / 2$ & $1 / 3$ & 3 & 2 & 3 & 3 \\
\hline B & $1 / 2$ & $1 / 2$ & 2 & 2 & 1 & 2 & 2 & 3 & 4 & 4 \\
\hline $\mathbf{R}$ & $1 / 2$ & $1 / 2$ & 3 & 3 & $1 / 2$ & 1 & 2 & 3 & 4 & 4 \\
\hline T1 & $1 / 3$ & $1 / 3$ & $1 / 2$ & $1 / 3$ & $1 / 2$ & $1 / 2$ & 1 & 2 & 3 & 3 \\
\hline T2 & $1 / 4$ & $1 / 4$ & $1 / 3$ & $1 / 2$ & $1 / 3$ & $1 / 3$ & $1 / 2$ & 1 & 4 & 4 \\
\hline S1 & $1 / 3$ & $1 / 3$ & $1 / 3$ & $1 / 3$ & $1 / 4$ & $1 / 4$ & $1 / 3$ & $1 / 4$ & 1 & $1 / 2$ \\
\hline S2 & $1 / 3$ & $1 / 3$ & $1 / 3$ & $1 / 3$ & $1 / 4$ & $1 / 4$ & $1 / 3$ & $1 / 4$ & 2 & 1 \\
\hline$* \mathrm{~W}$ & 0.18798 & 0.18798 & 0.09023 & 0.07404 & 0.13747 & 0.13392 & 0.06653 & 0.05591 & 0.03074 & 0.03521 \\
\hline
\end{tabular}

In the third step, the type and the data of membership functions used for each objective have been determined (Table 03) and the WAFGP model has been formulated as follows:

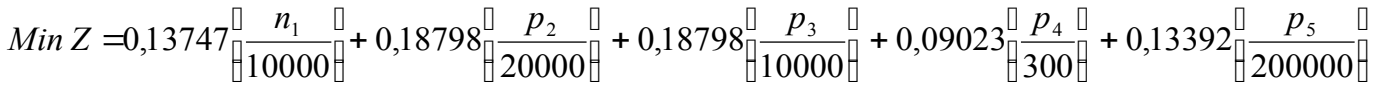

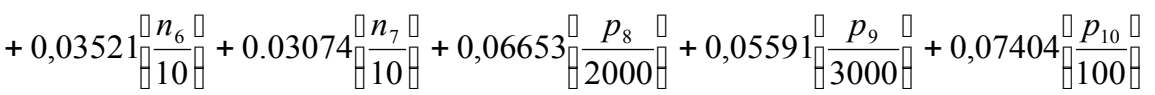

subjet to : 
ISAHP Article: A Style Guide for Paper Proposals To Be Submitted to the International Symposium on the Analytic Hierarchy Process 2016, London, U.K.

$$
\begin{array}{llll}
\sum_{i=1}^{10} B_{i} x_{i}+n_{1} \geq 480( & \sum_{i=1}^{10} P R D_{i} x_{i}+n_{6} \geq 47 & u_{2}+\frac{1}{20000}=1 & u_{8}+\frac{1}{2000}=1 \\
\sum_{i=1}^{10} h_{i} x_{i}-p_{2} \leq 650( & \sum_{i=1}^{10} P R U_{i} x_{i}+n_{7} \geq 49 & u_{3}+\frac{1}{10000}=1 & u_{9}+\frac{1}{3000}=1 \\
\sum_{i=1}^{10} S_{i} x_{i}-p_{3} \leq 280( & u_{4}+\frac{1}{300}=1 & u_{10}+\frac{1}{100}=1 \\
\sum_{i=1}^{10} O_{i} X_{i} x_{i}-p_{4} \leq 360 & \sum_{i=1}^{10} t t_{i} x_{i}-p_{9} \leq 0 & u_{5}+\frac{1}{200000}=1 & x_{1}=1 \\
\sum_{i=1}^{10} r_{i} b_{i} x_{i}-p_{5} \leq 0 & \sum_{i=1}^{10} m_{i} x_{i}-p_{10} \leq 11( & u_{6}+\frac{1}{10}=1 & \sum_{i=1}^{10} x_{i}=5 \\
& u_{1}+\frac{1}{10000}=1 & u_{7}+\frac{1}{10}=1 & x_{i}=0 \text { or } 1 \\
& &
\end{array}
$$

Where $: B_{i}=$ the benefit derived from implementing project $i, h_{i}=$ the hardware cost associated with implementing project $\mathrm{i}, \mathrm{S}_{\mathrm{i}}=$ the software cost associated with implementing project $\mathrm{i}, \mathrm{O}_{\mathrm{i}}=$ the other costs associated with implementing project $\mathrm{i}, \mathrm{r}_{\mathrm{i}}=$ the likelihood of failure of project $i ; P R D_{i}=$ the decision-maker's preference for project $i, P R U_{i}=$ the user's preference for project $\mathrm{i}, \mathrm{t}_{\mathrm{i}}=$ the estimated completion time for project $\mathrm{i}, \mathrm{tt}_{\mathrm{i}}=$ the estimated training time required for project $\mathrm{i}, \mathrm{mi}=$ the cost of additional manpower for project $\mathrm{i}$, $p_{i}, n_{i}=$ the positive and negative deviation variables for the goals $\mathrm{i}, \mu_{i}=$ degree of membership functions for the goal i, i $=1,2, \ldots, n$ IS project goals.

In this model, $x i$ is a binary variable so that it takes the value of 1 if the project $i$ is selected, it takes the value 0 otherwise. Using the LINGO package, the obtained optimal solution is as follows: $x_{1}=1, x_{2}=0, x_{3}=1, x_{4}=0, x_{5}=0, x_{6}=0, x_{7}=0, x_{8}=1$, $x_{9}=1, x_{10}=1$. The proposed model determines degree of membership functions for the ith goal:

$\left(\mu_{1}, \mu_{2}, \mu_{3}, \mu_{4}, \mu_{5}, \mu_{6}, \mu_{7}, \mu_{8}, \mu_{9}, \mu_{10}\right)=(0.87,1,1,1,0.341, \quad 0.11,0.53,0.60,0.840 .89,0.93)$

\section{Limitations}

Despite its advantages, the methodology proposed here neglected the uncertain nature of decision maker's judgment and the interdependencies among IS projects.

\section{Conclusions}

The IS project selection approach offered here combines the AHP within the WAFGP. The AHP is first used to estimate the decision criteria weights. These weights are used to formulate a WAFGP model and to complete the project selection decision. In comparison with the previews methodologies, this on deals with the imprecise data in IS projects and seems to be easier and simpler. Despite its advantages, this approach neglects the uncertain nature of decision maker's judgment and the interdependencies among IS projects. To overcome this limits, a hybrid models using fuzzy ANP and fuzzy parameters could be developed in the future.

\section{Key References}

Bolat, B., \& Çebi, F., \& Temur, G.T., \& Otay, İ. (2014). A fuzzy integrated approach for project selection. Journal of Enterprise Information Management, 27(3), 247 - 260.

Lee, J.W., \& Kim, S.H. (2001). An integrated approach for interdependent information system project selection. International Journal of Project Management, 19, 111-118.

Saaty, T.L. (1980). The Analytic Hierarchy Process. McGraw-Hill, New York. 
ISAHP Article: A Style Guide for Paper Proposals To Be Submitted to the International Symposium on the Analytic Hierarchy Process 2016, London, U.K.

Schniederjans, M.J, \& Wilson, R.L. (1991), Using the analytic hierarchy process and goal programming for information system project selection. Information \& Management, 20, 333-342.

Yaghoobi, M. A., Jones, D. F., \& Tamiz, M. (2008). Weighted Additive Models For Solving Fuzzy Goal Programming Problems, Asia Pac. J. Oper. Res., 25, 7156-733.

\section{Appendices}

Table 02: The model data inputs

\begin{tabular}{|c|c|c|c|c|c|c|c|c|c|c|c|}
\hline Project & Mandated & Benefit* & $\begin{array}{l}\text { Hard- } \\
\text { ware } \\
\text { Cost* }\end{array}$ & $\begin{array}{l}\text { Soft- } \\
\text { ware } \\
\text { cost* }\end{array}$ & $\begin{array}{l}\text { Other } \\
\text { Cost* }\end{array}$ & $\begin{array}{l}\text { Decision- } \\
\text { Makers } \\
\text { preferences }\end{array}$ & $\begin{array}{c}\text { Users } \\
\text { preference } \\
\text { s }\end{array}$ & $\begin{array}{l}\text { Risk } \\
\text { factor }\end{array}$ & $\begin{array}{c}\text { Completion } \\
\text { Time** }\end{array}$ & $\begin{array}{l}\text { Training } \\
\text { Time*** }\end{array}$ & $\begin{array}{c}\text { Annual } \\
\text { Cost for } \\
\text { Additional } \\
\text { Manpower* }\end{array}$ \\
\hline 1 & Yes & 1774 & 1900 & 3800 & 00 & 9.336 & 9.762 & 3 & 50 & 90 & 500 \\
\hline 2 & No & 1349 & 11500 & 2254 & 160 & 9.305 & 9.638 & 3 & 43 & 18 & 286 \\
\hline 3 & No & 40600 & 29500 & 16020 & 00 & 9.349 & 9.773 & 4 & 90 & 19 & 545 \\
\hline 4 & No & 1200 & 21000 & 7800 & 18 & 7.727 & 8.008 & 3 & 60 & 66 & 29 \\
\hline 5 & No & 5000 & 20000 & 750 & 190 & 9.272 & 9.505 & 2 & 83 & 84 & 294 \\
\hline 6 & No & 3000 & 14000 & 44 & 20 & 8.661 & 9.517 & 2 & 67 & 136 & 100 \\
\hline 7 & No & 2090 & 320 & 16000 & 00 & 9.206 & 9.377 & 3 & 91 & 69 & 00 \\
\hline 8 & No & 1300 & 500 & 1000 & 30 & 8.604 & 9.286 & 3 & 97 & 119 & 00 \\
\hline 9 & No & 1320 & 1200 & 3300 & 08 & 7.552 & 8.193 & 2 & 28 & 61 & 39 \\
\hline 10 & no & 1720 & 00 & 2500 & 10 & 7.481 & 8.002 & 2 & 36 & 24 & 23 \\
\hline $\begin{array}{l}\text { Maximum } \\
\text { available }\end{array}$ & ----------- & 48000 & 65000 & 28000 & 360 & 47 & 49 & ------- & ------------ & ---------- & 1100 \\
\hline
\end{tabular}

Table 03: Type and data of memberships function for every goal

\begin{tabular}{|c|c|c|c|}
\hline objective & Type of membership functions & \multicolumn{2}{|c|}{ data of membership functions } \\
\hline Benefit-related objective & Type 2 & $\left(\Delta_{i L}, b_{i}\right)$ & $(10000,48000)$ \\
\hline Hardware cost-related objective & Type 1 & $\left(b_{i}, \Delta_{i R}\right)$ & $(65000,20000)$ \\
\hline Software cost-related objective & Type 1 & $\left(b_{i}, \Delta_{i R}\right)$ & $(28000,10000)$ \\
\hline Other cost-related objective & Type 1 & $\left(b_{i}, \Delta_{i R}\right)$ & $(360,300)$ \\
\hline Risk-related objective & Type 1 & $\left(b_{i}, \Delta_{i R}\right)$ & $(0,200000)$ \\
\hline Preference-related objectives & Type 2 & $\left(\Delta_{i L}, b_{i}\right)$ & $(10,47)$ \\
\hline Preference-related objectives & Type 2 & $\left(\Delta_{i L}, b_{i}\right)$ & $(10,49)$ \\
\hline Completion time required & Type 1 & $\left(b_{i}, \Delta_{i R}\right)$ & $(0,2000)$ \\
\hline Training time required & Type 1 & $\left(b_{i}, \Delta_{i R}\right)$ & $(0,3000)$ \\
\hline Additional manpower required & Type 1 & $\left(b_{i}, \Delta_{i R}\right)$ & $(1100,100)$ \\
\hline
\end{tabular}

